https://helda.helsinki.fi

\title{
The prevalence and correlates of anticoagulant rodenticide exposure in non-target predators and scavengers in Finland
}

\section{Koivisto, Elina}

2018-11-15

Koivisto , E , Santangeli , A, Koivisto , P , Korkolainen , T , Vuorisalo , T , Hanski , I K, Loivamaa , I \& Koivisto , S 2018 , ' The prevalence and correlates of anticoagulant rodenticide exposure in non-target predators and scavengers in Finland ', The Science of the Total Environment , vol. 642 , pp. 701-707 . https://doi.org/10.1016/j.scitotenv.2018.06.063

http://hdl.handle.net/10138/316142

https://doi.org/10.1016/j.scitotenv.2018.06.063

cc_by_nc_nd

acceptedVersion

Downloaded from Helda, University of Helsinki institutional repository.

This is an electronic reprint of the original article.

This reprint may differ from the original in pagination and typographic detail.

Please cite the original version. 


\section{The prevalence and correlates of anticoagulant rodenticide exposure}

2 in non-target predators and scavengers in Finland

4 Elina Koivisto $^{1{ }^{\dagger *}}$, Andrea Santangeli $^{2}$, Pertti Koivisto ${ }^{3}$, Tapio Korkolainen ${ }^{4}$, Timo Vuorisalo ${ }^{1}$,

5 Ilpo K. Hanski ${ }^{2}$, Iida Loivamaa ${ }^{3}$, Sanna Koivisto ${ }^{4}$

6

7

$8{ }^{1}$ University of Turku, Department of Biology, FI-20014 Turun yliopisto, Finland

$9{ }^{2}$ The Helsinki Lab of Ornithology, Finnish Museum of Natural History, University of

10 Helsinki, P.O. Box 17, FI-00014, Helsinki, Finland

$11{ }^{3}$ Finnish Food Safety Authority Evira, Mustialankatu 3, FI-00790 Helsinki, Finland

$12{ }^{4}$ Finnish Safety and Chemicals Agency Tukes, P.O. Box 66, FI-00251 Helsinki, Finland

13

14 Current address: Finnish Environment Institute (SYKE), Joensuu, Oulu, and Helsinki

15 Offices, P.O. Box 140, FI-00251 Helsinki, Finland

16 * Corresponding author: Elina Koivisto, Tel: +358-41-4492300, fax: +358-29-4505050,

17 email: elanko@utu.fi 


\section{Highlights}

\section{Abstract}

27 The most common rodent control method worldwide is anticoagulant rodenticides (ARs), 28 which cause death by internal bleeding. ARs can transfer to non-target predators via positive relationship between the coumatetralyl concentration and the livestock farm density.

39 Conversely, overall AR concentration and number, as well as the concentration of three separate ARs (coumatetralyl, difenacoum and bromadiolone) differed among the three

41 species groups tested, with the group "other mammals" (largely represented by red fox and

- Anticoagulant rodenticides (ARs) were detected in $82 \%$ of the samples

- Bromadiolone was the most prevalent AR and was also found in highest concentrations

- Species group explained most variation in prevalence and concentrations

- Group represented by foxes and raccoon dogs had the highest values

\section{https://www.sciencedirect.com/science/article/pii/S004896971832134X} secondary exposure, i.e. by consuming contaminated rodents. Here we quantify the prevalence of seven AR substances in the liver tissues of altogether 17 mammalian or avian predator or scavenger species in Finland. In addition, we identify the environmental and biological factors potentially linked to secondary AR poisoning. No previous AR screenings have been conducted in the country, despite the widespread use of ARs and their potential impacts on the high levels of the ecosystem food chain. ARs were detected $(\geq 0.3 \mu \mathrm{g} / \mathrm{kg})$ in $82 \%$ of the 131 samples. The most prevalent and the AR with highest concentrations was bromadiolone (65\% of samples). In $77 \%$ of the positive samples more than one (2-5) different ARs were detected. Of the environmental variables, we only found a weakly raccoon dog) having higher values than the groups presented by mustelids or by birds. ARs 
43 are authorized only as biocides in Finland and a national strategy on risk management (e.g.

44 for minimising secondary poisoning of non-target species) of ARs was adopted in 2011.

45 Based on these results it appears that the risk mitigation measures (RMMs) either have not

46 been followed or have not been effective in preventing wide scale secondary exposure.

47 Continued monitoring of AR residues in non-target species is needed in order to evaluate the

48 effectiveness of current RMMs and a need for new ones to reduce the risk of secondary

49 poisoning.

50

51 Graphical abstract
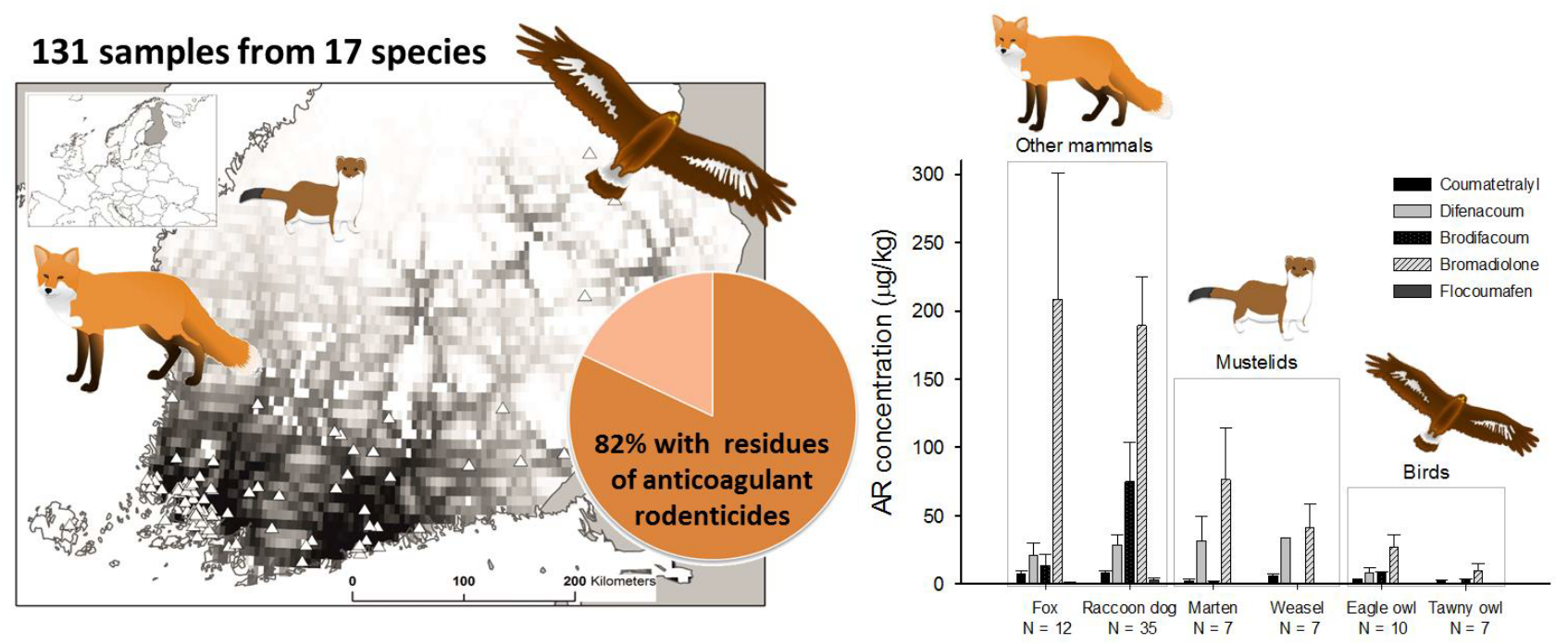

52

53

54 Keywords: Non-target exposure, Residues monitoring, Secondary poisoning 


\section{1. Introduction}

56 Under the impelling pressure to increase food production after World War II, the farming and

57 food industry has progressively increased the use of chemical substances. Since 1950, the

58 global pesticide use has risen more than 50-fold (Miller 2005). Substances such as herbicides

59 and insecticides have become particularly widespread, and their presence in the environment

60 has been often found to have detrimental secondary impacts on wildlife, and also on humans

61 (Carson 1962; Pain and Pienkowski 1997). Rodents are among one of the most common,

62 generalist and widespread pests, causing a number of damages to agriculture and public

63 health, and are the target of widespread pest control campaigns (Singleton 2003). The most

64 common method used for rodent control worldwide is anticoagulant rodenticides (ARs). All

65 ARs have a similar chemical structure and the same mode of action: they act by blocking the

66 vitamin $\mathrm{K}$ cycle, resulting in inability to produce essential blood-clotting factors, thereby

67 leading to death by internal bleeding (Berny et al. 2014). These effects are gradual, typically

68 developing over several days.

69 Anticoagulants can be divided into first and second generation substances. The first

70 generation anticoagulant rodenticides (FGARs) are less toxic and are eliminated within days,

71 thereby requiring multiple doses to be fatal. The second generation anticoagulant rodenticides

72 (SGARs) were developed after rodents started to show resistance to first generation agents,

73 and they are toxic at a much lower dose (IPCS 1995). SGARs are persistent or very

74 persistent, bioaccumulative or very bioaccumulative and toxic (European Chemicals Agency,

75 Biocidal Products Committee opinions on active substance approval,

76 http://dissemination.echa.europa.eu/Biocides/factsheet?id=0018-14). Anticoagulants have

77 been found to transfer to non-target animals either by direct consumption of baits (primary

78 poisoning) or by consuming contaminated prey animals (secondary poisoning, Lambert et al. 
79 2007). Rodenticides are generally placed within bait boxes inaccessible to large animals. The

80 target rodent that ingested the rodenticide will only die within a few days following the

81 ingestion of lethal dose (Vandenbroucke et al. 2008). During this phase the rodent may be

82 consumed by predators, causing secondary poisoning. Rodents dying aboveground can in

83 turn represent an important risk of secondary poisoning for scavengers (Montaz et al. 2014).

84 Several species of mammalian and avian predators have been found to be exposed to ARs

85 worldwide (see López-Perea and Mateo 2018 for a review), for example red foxes (Vulpes

86 vulpes; Geduhn et al. 2015), mustelids (Mustela sp.; Elmeros et al. 2011), red kites (Milvus

87 milvus; Berny and Gaillet 2008) and barn owls (Tyto alba; Newton et al. 1990). Besides in

88 rodent-eating predators, ARs have also been found in non-target small mammals (e.g.

89 Geduhn et al. 2014), and in insectivorous species, like European hedgehogs (Erinaceus sp.,

90 Dowding et al. 2010, López-Perea et al. 2015), shrews (Sorex sp., Geduhn et al. 2014) and

91 passerine birds (Masuda et al. 2014). Anticoagulant poisoning is also a major issue for

92 domestic animals, especially dogs (Berny et al. 2010 and references therein).

93 Quantifying the prevalence level of secondary AR poisoning in non-target wildlife is

94 challenging, due to biases in the sample collection and to lab techniques to detect the

95 prevalence of the substances. Moreover, the AR dosages acquired by consuming a poisoned

96 rodent, for example, may be too low to have lethal consequences. However, in France

97 intensive bromadiolone control following water vole (Arvicola terrestris) outbreaks has been

98 reported to have caused considerable number of deaths of red kites and common buzzards

99 (Buteo buteo; Coeurdassier et al. 2014). Wildlife AR poisoning and the unintentional wildlife

100 deaths caused primarily or partially by ARs are systematically monitored only in few

101 countries (e.g. SAGIR network in France, Millot et al. 2017), hence we still lack knowledge

102 on the extension of problems caused by ARs to non-target wildlife from most countries. The

103 potential sublethal and population level effects of secondary AR poisoning are even less 
104 known or evaluated (but see Naim et al. 2010, Martínez-Padilla et al. 2017). However, 105 repercussions could be important at the high levels of the food chain, because of the 106 potentially increased dosage, and because the target species may be more sensitive to 107 environmental change, e.g. pollution (as is the case for raptors; Newton 1998). There is thus a 108 need to establish wider study schemes around the world both to assess the prevalence and 109 associated risks caused by ARs, and to evaluate risk mitigation measures and eventually 110 adjust them based on newly available information.

111 In Finland anticoagulant rodenticides are only authorized and predominantly used as 112 biocides, and use for the crop protection is scarce. A national strategy on risk management of 113 ARs was adopted in 2011. Rodenticides were regulated under pesticide acts until the end of 114 2006. They could be used for plant protection use (mainly to protect saplings) and for 115 biocidal use. From beginning of 2007 rodenticides started to be regulated as biocides. The 116 anticoagulant active substances found in this study have been on market in Finland at least 117 since 1998. The most commonly used AR is bromadiolone. There has been no specific 118 strategy or RMMs apart from the label claims. The use of ARs has not been studied in 119 Finland, but it has most likely remained the same until 2011 and even after that despite of 120 attempts of authorities to enlighten users of risk to non-target animals. There is still no 121 surveillance or monitoring of use of ARs.

122 No AR screenings have ever been conducted in the country, despite the widespread use of 123 ARs and their potential impacts on the high levels of the ecosystem food chain. Here we 124 quantify the prevalence of anticoagulant rodenticide substances (FGARs chlorophacinone 125 and coumatetralyl, SGARs brodifacoum, bromadiolone, difenacoum, difethialone, and 126 flocoumafen) in the liver tissues of altogether 17 mammalian or avian predator or scavenger 127 species (group "other mammals": domestic cat, raccoon dog, brown rat, red fox; group 128 "mustelids": stoat, badger, least weasel, otter, pine marten; group "birds": eagle owl, 
129 goshawk, hooded crow, hen harrier, magpie, sparrow hawk, white-tailed sea eagle, tawny 130 owl). In addition, we aim to identify the environmental (e.g. distance to industrial areas,

131 which are typical areas for AR use) and biological factors (e.g. species group reflecting 132 habitat use and diet preferences) that could be linked to secondary AR poisoning.

134 2. Material and methods

\section{$135 \quad 2.1$ Sample collection}

136 Liver samples were collected to determine the concentrations of the seven anticoagulant

137 rodenticide substances (brodifacoum, bromadiolone, difenacoum, difethialone, flocoumafen,

138 coumatetralyl, chlorophacinone) approved in Finland from altogether 131 individuals of

139 different predator and scavenger species (group "other mammals": domestic cat, raccoon dog,

140 brown rat, red fox; group "mustelids": stoat, badger, least weasel, otter, pine marten; group

141 "birds": eagle owl, goshawk, hooded crow, hen harrier, magpie, sparrow hawk, white-tailed

142 sea eagle, tawny owl. Please see Table A.1 for more details). Animals were either found dead

143 (e.g. road-kills) or were shot or trapped as part of predator removals from conservation areas

144 (namely raccoon dog Nyctereutes procyonoides, which is an alien species in Finland).

145 Samples were collected by the Zoological museums of the Universities of Turku and

146 Helsinki, originally provided by museum personnel and private citizens. Most samples were

147 collected in autumn-winter 2014 but some of the samples were of an older origin (mainly

148 from years 2004-2013). The study species were selected because they are common species in

149 Finland and because they are known to prey or scavenge on small animals. The species (listed

150 in Table A.1 and Figure 2) included mainly rodent-eating predators, omnivores and

151 scavengers, and as a reference also few carnivorous species that are not using rodents as their 
main food source. In addition we had samples of a target species of ARs (brown rat Rattus norvegicus) from areas with known AR use. Samples were collected mostly from southwestern of Finland (Figure 1) and largely close to accessible areas (i.e. in the vicinity of human settlements) where exposure to the anticoagulants is most probable.

156 Samples were taken from the liver, since anticoagulants accumulate in the liver and their 157 concentrations are low in other tissues (Fournier-Chambrillon et al. 2004). In most cases, the 158 liver as whole was taken from the carcass. The coordinates of the sampling site along with 159 the species and sex of the animal where marked to the sample. Body mass was measured and 160 ages defined whenever possible. Liver samples were stored in a freezer $\left(-18^{\circ} \mathrm{C}\right)$.

161

\section{$162 \quad 2.2$ Analytics}

163 The concentrations of seven rodenticides in liver samples were determined by a UHPLC 164 triple quadrupole mass spectrometric method. An external standard method was used for the 165 quantification. Deuterated warfarin was used for confirming success of the sample 166 preparation. The compound was not used as internal standard for calibration purposes, but 167 only as an indicator of successful extractions.

\subsubsection{Sample preparation}

170 Defrosted liver samples were homogenised in a blender and pushed through a metal sieve.

171 Thereafter water-acetonitrile $(5 \mathrm{~mL}, 1: 1)$ was added to the samples and they were vortexed 30 172 seconds and sonicated in ultrasonic path for 10 minutes. To the sonicated sample ca. $1 \mathrm{~g}$ of 173 sodium chloride was added. Following this the samples were vortexed and re-incubated in a 174 sonic bath (10 minutes) and centrifuged 5 minutes at $3000 \mathrm{rpm}$. The upper (organic layer) 
175 phases were transferred to other test tubes. To the remaining tissue material tubes $2.5 \mathrm{~mL}$ of 176 acetonitrile (ACN) was added and the sonication and centrifugation steps were repeated 177 twice.

178 The ACN phases containing the analytes were transferred into new test tubes and evaporated 179 to dryness under a stream of nitrogen (Turbovap evaporator). The dry residues were re180 dissolved into $\mathrm{ACN}$ and sonicated after addition of an aliquot of purified water $(25 \% \mathrm{ACN}$ at 181 final concentration). The samples were eluted through SPE columns and the columns were 182 washed with $25 \%$ methanol $(2 \mathrm{~mL})$. Analytes were eluted from the column using $5 \mathrm{~mL}$ of 183 ACN containing ammonium hydroxide (5\%). Solvent was again evaporated to dryness under 184 a stream of nitrogen. The dry samples were dissolved into methanol $(90 \%, 0.5 \mathrm{~mL})$ and 185 filtered through $0.2 \mu \mathrm{m}$ syringe filter to UHPLC-vials.

188 A UHPLC instrument equipped with C-18 $1.7 \mu \mathrm{m}(2.1 \times 100 \mathrm{~mm})$ column was applied. Eluents 189 were $10 \mathrm{mM}$ ammonium formate $(\mathrm{pH} 9.5)$ and methanol $(\mathrm{MeOH})$. Linear gradient: from $20 \%$ $190 \mathrm{MeOH}$ to $70 \% \mathrm{MeOH}$ in 5 or 6 minutes was used. Methanol was increased to $95 \%$ and kept $19130 \mathrm{sec}$. at $95 \%$ and from 6.5 to $7 \mathrm{~min}$ descending gradient to $20 \% \mathrm{MeOH}$. Column 192 temperature was kept at $35^{\circ} \mathrm{C}$ and eluent flow rate was $0.35 \mathrm{~mL} / \mathrm{min}$. Injection volume was $1935.0 \mu \mathrm{L}$ and total run time was 10 minutes. Corresponding retention times were: brodifacoum 194 c. $6.4 \mathrm{~min}$, bromadiolone c. 6.1 and $6.2 \mathrm{mins}$ (two isomers), difenacoum c. $6.2 \mathrm{~min}$, 195 difethialone c. $6.5 \mathrm{~min}$, flocoumafen c. $6.35 \mathrm{~min}$, chlorophacinone c. $5.5 \mathrm{~min}$, coumatetralyl c. 3.6 min and warfarin D5 $3.1 \mathrm{~min}$. 
199 The determinations were carried out with Xevo TQ-ms triple quadrupole instrument.

200 Negative electrospray ionisation was used for all compounds. MS transitions for quantitation

201 were: brodifacoum $521.3>135.0$, bromadiolone $525.3>250.0$, difenacoum $443.5>135.0$,

202 difethialone 537.3 >151.0, flocoumafen $541.4>161.0$, chlorophacinone $373.2>201.0$,

203 coumatetralyl $291.3>141.0$.

204

$205 \quad$ 2.2.4 Calibration range and linearity

206 Five standard samples were prepared for each analytical batch by spiking AR-free porcine

207 liver with known amounts of the substances. The concentrations that were used were 1, 5, 20,

20850 and $300 \mu \mathrm{g} / \mathrm{kg}$. Correlation coefficients $\left(\mathrm{R}^{2}\right)$ for the calibration lines were typically 0.98 2090.99.

210

211

\subsubsection{Recovery}

212 Recovery was tested by spiking porcine liver sample with $20 \mu \mathrm{g} / \mathrm{kg}$ of anticoagulant mixture 213 compared to standards without purification step. Recoveries $(\mathrm{N}=3)$ were for brodifacoum $214(17 \pm 30 \%)$, bromadiolone $(35 \pm 21 \%)$, difenacoum $(11 \pm 41 \%)$, difethialone $(12 \pm 50 \%)$, 215 flocoumafen $(22 \pm 38 \%)$, coumatetralyl $(59 \pm 26 \%)$, and chlorophacinone $(20 \pm 52 \%)$. In 216 comparison to pure standards a recovery of analysed anticoagulants was too low and as a

217 result matrix added calibration of curves was made for each sample set. In this way sample 218 analysis it is not necessary to make recovery correction. 
221 The limit of quantification (LOQ) was set to $1.0 \mu \mathrm{g} / \mathrm{kg}$ wet tissue for brodifacoum, bromadiolone, difenacoum, difethialone, flocoumafen and coumatetralyl, however, for chlorophacinone it was $20 \mu \mathrm{g} / \mathrm{kg}$. The limit of detection (LOD) for six of the substances was $0.3 \mu \mathrm{g} / \mathrm{kg}$, except for chlorophacinone it was $5.0 \mu \mathrm{g} / \mathrm{kg}$. Signal to noise value 10 was used as minimum allowable peak integration level.

\subsection{Environmental drivers and statistical analyses}

228

We then assessed the relationship between $\mathrm{AR}$ substances and relevant environmental covariates. The sample unit for these analyses was the single observation (the AR value measured in the tissue of each sample) yielding a total of 131 samples where ARs were measured from the specimen and where the coordinates of the collection place were known, thus allowing the calculation of landscape variables (see below). These landscape variables included the density of livestock farms, the density of cereal farms with no livestock, as well as the distance to the closest industrial settlement. These three variables were extracted in GIS from original layers depicting the location of farms and industrial settings, and the values for the variables were calculated from the point where the sample was collected. The presence of farms (particularly livestock farms) has been linked to the prevalence of ARs in red fox tissues (Geduhn et al. 2015). Distance to the closest industrial setting was considered here as ARs are commonly used in such places to control or prevent rodent infestations. This variable is however strongly correlated with many other similar variables depicting distance

241 from other infrastructures such as houses of different types, schools and the like.

242 Furthermore, we also considered a categorical variable depicting three groups of species 243 (birds, mustelids, other mammals), and a categorical variable depicting how the sample was 
244 found (shot or trapped, road-kill, other or unknown). Because the number of analysed 245 samples was low (e.g. < 10; see supporting Table A.1.) for many of the species, it was not 246 possible to correlate species-level traits (such as diet and habitat preference) to the AR 247 substances found in the specimens, hence the pooling of species into three broad categories as 248 detailed above.

249 We built five separate full models including all the five above mentioned predictors. Four 250 models had as response variable in turn the total concentration of all ARs together, as well as 251 concentration of coumatetralyl, difenacoum and bromadiolone (using linear regression with 252 Gaussian distribution and identity link). A fifth model included the number of different AR 253 substances found in each sample (using a Poisson distribution with log link). For each of the 254 five separate models, we started with the full model (including all five predictors), and 255 proceeded with model comparison and multimodel inference using Akaike Information 256 Criterion (AIC) following the approach of Burnham and Anderson (2002). We run all model combinations with the five variables in each case and then derived model averaged coefficients and statistics from the set of best ranked models (i.e. with AIC $<4$ ) using the package MuMin (Bartoń 2011) in R version 3.0.3 (R Core Team 2015). Prior to analyses, we scaled and centred all the three continuous predictors to aid convergence, and we log transformed the four response variables depicting concentrations of AR to reduce the spread of these data and the occurrence of outliers. Collinearity among predictor variables was checked by means of variance inflation factor (VIF) analysis. All variables had a VIF value < 3, suggesting low collinearity, thus their inclusion in the same model is appropriate (Zuur et al. 2009). It was not possible to run the above models using brodifacoum and flocoumafen concentrations as responses because most of the competing sub-models for these failed to converge. 


\section{Results}

\section{$270 \quad 3.1$ Prevalence of anticoagulant rodenticides}

271 Anticoagulant rodenticide residues were detected $(\geq 0.3 \mu \mathrm{g} / \mathrm{kg})$ in $82 \%$ of the 131 samples

272 analysed (Figure 2a). Of the analysed ARs, chlorophacinone and difethialone were not found

273 in any of the samples. Of the detected ARs, the most common substance was bromadiolone

274 (found in $65 \%$ of the analysed samples), followed in decreasing order of commonness by

275 coumatetralyl (48\%), difenacoum (42\%), brodifacoum (23\%) and lastly flocoumafen (12\%).

276 In $77 \%$ of the positive samples more than one (2-5) different ARs were detected (Figure 2b).

277 ARs were commonly detected e.g. in foxes, raccoon dogs, mustelids and owls (Figure 2a). Of

278 these, foxes and raccoon dogs had the highest observed concentrations (Figure 3).

279 Concentrations of bromadiolone were the highest among all ARs analysed, while

280 brodifacoum and difenacoum showed moderate concentrations, and coumatetralyl (the only

281 first generation substance) and flocoumafen were very scarce (Table A.1, Figure 3).

282

$283 \quad 3.2$ Environmental drivers

284 Overall, we found no effect of environmental variables, such as the density of farms with or

285 without livestock, and the distance to the closest industrial setting, on any of the five response

286 variables considered (Table 1). The only exception is represented by a weakly positive

287 relationship between the concentration of coumatetralyl in the samples and the density of

288 livestock farms (Table 1).

289 Conversely, overall AR concentration and number, as well as the concentration of each of the

290 three ARs separately differed among the three species groups tested, with other mammals

291 (largely represented by red fox and raccoon dog samples) having higher values than 
292 mustelids and birds (see Table A.2, Figure 2b, Figure 3). In the case of difenacoum, the 293 concentration was also significantly higher for samples that were shot or trapped (LS mean $=$ 294 1.31, $\mathrm{SE}=0.18$ ) as compared to the other samples (road-kill: $\mathrm{LS}$ mean $=0.56, \mathrm{SE}=0.29$, 295 other or unknown: $\mathrm{LS}$ mean $=0.45, \mathrm{SE}=0.26$ ). 


\section{Discussion}

297 Here we quantified the prevalence of anticoagulant rodenticide (AR) substances in liver samples of non-target mammalian or avian predator or scavenger species susceptible for secondary AR exposure for the first time in Finland. Residues of AR substances were found in most of the samples analysed (in $82 \%$ of 131 samples from 17 species). Apart from chlorophacinone and difethialone which have not been on the market in Finland so far despite of the authorization, all the other five analysed substances (coumatetralyl, brodifacoum, bromadiolone, difenacoum and flocoumafen) were detected. Of these, bromadiolone was the most commonly detected one and it also had the highest observed concentrations. In $77 \%$ of the positive samples more than one (2-5) different ARs were detected. In addition, we identified the environmental and biological factors potentially linked to secondary AR poisoning. Overall, we found no effect of the studied environmental variables (e.g. distance to the closest industrial setting), except for a weakly positive relationship between the concentration of coumatetralyl and the density of livestock farms. Conversely, overall AR concentration and number, as well as the concentration of three of the ARs (coumatetralyl, difenacoum and bromadiolone) separately differed among the three species groups tested, with the group "other mammals" (largely represented by fox and raccoon dog samples) having higher values than groups "mustelids" (e.g. least weasels and stoats) and "birds" (e.g. eagle owls and hooded crows).

\subsection{Prevalence and concentrations of anticoagulant rodenticides}

317 The most common substance found was bromadiolone, which is also the most commonly used AR in Finland. Concentrations of bromadiolone were also the highest among all ARs analysed. In general, the prevalence of the ARs in non-target species corresponded well with 
the sales of the substances in Finland. The sale volumes are collected yearly by the Finnish

Safety and Chemicals Agency (Tukes), but the information is confidential, hence the sales of separate products cannot be disclosed. The only first generation AR (FGAR), coumatetralyl, was found in $48 \%$ of the samples. This is a high prevalence compared to some other studies, e.g. prevalence of only 5.7\% in German red foxes found by Geduhn et al. (2015). Coumatetralyl may not be commonly used in many countries, due to prevalence of FGAR resistance (Geduhn et al. 2015). In Finland products containing coumatetralyl are not used frequently, but the concentration in the products is 7.5-81 times higher compared to second generation ARs (SGARs). Although coumatetralyl was found commonly in the samples, the concentrations were low compared to the SGARs. This is most probably due to the much shorter elimination half-life of coumatetralyl (1.8-4 days) compared to the SGARs (118-350 days). The half-lives of 118 days (difenacoum) and 350 days (brodifacoum) are given in the List of Endpoints (Chapter 3. Impact on Human Health, rate and extent of excretion) of the

(http://dissemination.echa.europa.eu/Biocides/factsheet?id=0026-14,

http://dissemination.echa.europa.eu/Biocides/factsheet?id=0011-14). The half-lives of coumatetralyl (1.8-4 days) are reported in the Document III-A, Data_001.pdf, Section 6.2 Toxicokinetics. http://dissemination.echa.europa.eu/Biocides/factsheet?id=0018-14).

In general, ARs were most often found in species which have a diet with a high percentage of rodents (e.g. owls, mustelids, red fox) as expected (López-Perea and Mateo 2018). The prevalence found in this study ( $82 \%$ over all samples) is high compared to some previous studies (see López-Perea and Mateo 2018 for a compilation table). For comparison, in the

342 Netherlands the prevalence found in the predatory birds studied was $50 \%$ (van den Brink $3432014 ; \mathrm{LOD}=10 \mu \mathrm{g} / \mathrm{kg}$ ), in Spain $38.7 \%$ in all the studied animals and $49.5 \%$ in nocturnal raptors and carnivorous mammals (Sánchez-Barbudo 2012; LODs = 1-6 $\mu \mathrm{g} / \mathrm{kg}$ ), and in 
345 France in raptors 73\% (Lambert et al. 2007; LOD $=80 \mu \mathrm{g} / \mathrm{kg}$ ). On the other hand, an equally

346 high prevalence was found e.g. in Denmark (84-100\% in all the avian and mustelid species

347 studied; Christensen et al. 2010; LODs $=2-3 \mu \mathrm{g} / \mathrm{kg}$ ) and USA (96\% in four species of birds

348 of prey; Murray 2017).

349 The high prevalence found could be due to several factors. First, the limits of detection

350 (LOD) for the ARs in the present study were quite low $(\geq 0.3 \mu \mathrm{g} / \mathrm{kg}$ ) compared to some of the

351 other studies (see above). Second, sample sizes for many species were quite low, increasing

352 the possibility of chance affecting the results. In addition, the samples were on purpose

353 collected mostly from accessible areas with dense human population and thus high potential

354 for AR exposure. Geduhn et al. (2015), for example, found local livestock density and the

355 percentage of urban area to be good indicators for AR residue occurrence in red foxes. Higher

356 exposure to ARs in predators from urban areas has also been observed in other studies (e.g.

357 Riley at al 2007, López-Perea et al. 2015). The prevalence of AR exposed animals is also

358 known to decrease with increasing distance to baiting boxes (Geduhn et al. 2014,

359 Miljøministeriet 2015). In densely human populated areas the patches where no baiting is

360 conducted are probably scarce, and considering the large hunting areas of the mobile

361 predators (Hunter 2011), their likelihood of AR exposure in urban areas is probably very high

362 (see Hindmarch and Elliott 2018 for review).

363 Although the prevalence was high, the concentrations found in this study were rather low.

364 The potentially lethal level for SGAR residues in barn owls has been described as > 100

$365 \mu \mathrm{g} / \mathrm{kg}$ (Newton et al. 1999a) and $>200 \mu \mathrm{g} / \mathrm{kg}$ (Newton et al. 1999b). Overall, the majority of

366 the concentrations found in this study were below these ranges and thus probably not lethal

367 for the animals. However, the highest concentration found was $920 \mu \mathrm{g} / \mathrm{kg}$ of bromadiolone in

368 a fox. Besides direct lethal effects, ARs can have negative effects on non-target animals also

369 in other more subtle ways such as impairing reproduction or body condition. For example, 
370 common kestrel (Falco tinnunculus) fledglings with bromadiolone in their blood, regardless

371 of the concentration, have been found to have a lower body mass than those without

372 detectable bromadiolone (Martínez-Padilla et al. 2015). AR residues have also been

373 hypothesized to predispose for example bobcats (Lynx rufus) to other medical conditions such

374 as an inability to mount strong, anti-mite immunity (Riley et al. 2007, Serieys et al. 2013),

375 and recent findings indeed suggest that sublethal toxicant exposure may indirectly cause

376 mortality in bobcats by severely weakening their immune system (Serieys et al. 2018).

\section{$378 \quad 4.2$ Environmental drivers}

379 As a result of the study no remarkable effect of the environmental variables considered was

380 found. The lack of effect found could be due to the aggregated sample collection near

381 residential areas, thereby reducing the variance in the environmental covariates and masking

382 any possible impact. Alternatively, as AR prevalence and concentration differences were

383 largely driven by species group, the lack of effect of environmental drivers could reflect a

384 dominance of the species group "other mammals" in the samples. Raccoon dogs represented

385 almost a third of all the samples. Compared to other species studied, raccoon dogs and red

386 foxes had a high prevalence and highest concentrations found in the livers. Both species are

387 well-adapted to urban and semi-urban environments and have thus high probability to be

388 exposed to ARs, both directly and indirectly (Harris and Baker 2001, Kauhala and Ihalainen 389 2014).

390 Only a weakly positive relationship between the concentration of coumatetralyl in the 391 samples and the density of livestock farms could be estimated. Coumatetralyl is the only 392 active substance that has been available as a contact poison, which are not eaten by rodents, 
but groomed from the fur. Such poisons are favoured by farmers because the effectiveness of contact poisons is not hampered by the excess of food easily available on livestock farms.

\subsection{Conclusions}

397 Based on the high AR prevalence found in this study, it seems that the Risk Mitigation Measures (RMMs) to reduce collateral effects of ARs either have not been followed or have not been effective enough in preventing wide scale secondary exposure of the non-target animals in Finland. While the advice and guidance are seen as the major measures to reduce

401 harmful effects of the ARs, there would clearly be a need to increase surveillance and monitoring, which at current are completely lacking. Continued monitoring of AR residues in non-target species is needed in order to evaluate the effectiveness of current RMMs and adjust them accordingly.

405 Exposure of non-target wildlife is an unwanted, unnecessary, and unethical ramification of 406 AR use. Full prevention of secondary poisoning is not possible as long as ARs are used. 407 However, given the lack of knowledge of their potential effects on wildlife, it is very 408 important to apply a precautionary principle whereby RMMs like restriction to indoor use or 409 restriction to professional use only are designed and enforced to minimise the collateral 410 impacts of AR use on non-target species. The implications of this study span far beyond the 411 study system considered here. ARs are widely used across most countries in the world 412 (www.fao.org), including those in the global South where the most imperilled biodiversity 413 locates. Predators and scavengers play crucial ecosystem roles but are also at high risk of 414 extinction due to anthropogenic drivers (O'Bryan et al. 2018). The added threat due to secondary poisoning of predators and scavengers from ARs is largely unknown in many areas 416 yet could have ecosystem level repercussions. As such, we urge more studies investigating 
417 the prevalence of AR spilling across the different levels of the food chain. Only the evidence 418 gathered by these studies could drive the designation and implementation of effective 419 mitigation measures, such as risk management measures. These would ultimately allow for 420 rodent pest control while minimising spill-over impacts that represent a threat, to other non421 target species as well as humans.

422

\section{5. Acknowledgements}

424 This study was financially supported by the Finnish Ministry of Environment. We want to 425 thank all the people who have participated in the sample collection, especially Ari Karhilahti, 426 the staff of the zoological museums of the Universities of Helsinki and Turku, Anticimex Oy 427 and all the volunteers. Ville Välttilä is thanked for lab work and Niko Turunen for assisting in 428 analyses. Tiina Tuusa, Mikko Heini and Jouni Siltala are acknowledged for the comments on 429 the manuscript and Mari S. Lyly for animal drawings.

\section{6. References}

432

433

Bartoń K 2011. Package 'MuMIn'<http://cran.r-project.org/web/packages/MuMIn/index.html>. (Last accessed 434 25.01.15)

435

436

Berny PJ, Gaillet JR 2008. Acute poisoning of red kites (Milvus milvus) in France: data from the SAGIR

437 network. Journal of Wildlife Diseases 44: 417-426.

438

439 Berny PJ, Caloni F, Croubels S, Sachana M, Vandenbroucke V, Davanzo F, Guitart R 2010. Animal poisoning

440 in Europe. Part 2: Companion animals. The Veterinary Journal 183: 255-259. 
442 Berny PJ, Esther A, Jacob J, Prescott C 2014. Risk mitigation measures for anticoagulant rodenticides as 443 biocidal products. Final report. European Commission, Luxembourg.

Burnham KP, Anderson DR 2002. Model selection and multimodel inference: a practical information-theoretic approach, 2nd edn. Springer, New York.

447

Carson R 1962. Silent spring. Houghton Mifflin Company.

449

450

Christensen TK, Elmeros M, Lassen P 2010. Forekomst af antikoagulante rodenticider i danske rovfugle, ugler og små rovpattedyr. Faglig rapport fra DMU nr. 788.

452

Coeurdassier M, Riols R, Decors A, Mionnet A, David F, Quintaine T, Truchetet D, Scheifler R, Giraudoux P

2014. Unintentional wildlife poisoning and proposals for sustainable management of rodents. Conservation

Biology 28: 315-21.

456

Dowding CV, Shore RF, Worgan A, Baker PJ, Harris S 2010. Accumulation of anticoagulant rodenticides in a non-target insectivore, the European hedgehog (Erinaceus europaeus). Environmental Pollution 158: 161-166.

Elmeros M, Christensen TK, Lassen P 2011. Concentrations of anticoagulant rodenticides in stoats Mustela erminea and weasels Mustela nivalis from Denmark. Science of the Total Environment 409: 2373-2378.

462

Fournier-Chambrillon C, Berny JP, Coiffier O, Barbedienne P, Dassé B, Delas G, Galineau H, Mazet A, mustelids by anticoagulant rodenticides in France: Implications for the conservation of the European mink (Mustela lutreola). Journal of Wildlife Diseases 40: 688-695.

468 Geduhn A, Esther A, Schenke D, Mattes H, Jacob J 2014. Spatial and temporal exposure patterns in non-target 

practice and residues of anticoagulant rodenticides in red foxes (Vulpes vulpes). PLoS ONE 10(9): e0139191. doi:10.1371/journal.pone.0139191

Harris S, Baker P 2001. Urban foxes. British Natural History Series. Whittet Books, Suffolk.

Hindmarch S, Elliott JE 2018. Ecological Factors Driving Uptake of Anticoagulant Rodenticides in Predators. In: van den Brink N, Elliott J, Shore R, Rattner B (eds) Anticoagulant Rodenticides and Wildlife. Emerging Topics in Ecotoxicology (Principles, Approaches and Perspectives), vol 5. Springer, Cham.

480

Hunter LT 2011. Carnivores of the world. Princeton University Press.

IPCS 1995. Environmental Health Criteria 175. World Health Organization. ISBN 924157175 6, ISSN 0250 $863 X$.

485

Kauhala K, Ihalainen A 2014. Impact of landscape and habitat diversity on the diversity of diets of two omnivorous carnivores. Acta Theriologica 59: 1- 12.

488

Lambert O, Pouliquen H, Larhantec M, Thorin C, L'Hostis M 2007. Exposure of raptors and waterbirds to anticoagulant rodenticides (difenacoum, bromadiolone, coumatetralyl, coumafen, brodifacoum): Epidemiological survey in Loire Atlantique (France). Bulletin of Environmental Contamination and Toxicology 79: 91-94.

López-Perea JJ, Mateo R 2018. Secondary Exposure to Anticoagulant Rodenticides and Effects on Predators. In: van den Brink N, Elliott J, Shore R, Rattner B (eds) Anticoagulant Rodenticides and Wildlife. Emerging Topics in Ecotoxicology (Principles, Approaches and Perspectives), vol 5. Springer, Cham. region of Spain. Science of the Total Environment 511: 259-267. 
Martínez-Padilla J, López-Idiáquez D, López-Perea JJ, Mateo R, Paz A, Viñuela J 2017. A negative association vole outbreaks. Pest Management Science 73: 364-370.

505

506

Masuda BM, Fisher P, Jamieson IG 2014. Anticoagulant rodenticide brodifacoum detected in dead nestlings of an insectivorous passerine. New Zealand Journal of Ecology 38: 110-115.

Murray M 2017. Anticoagulant rodenticide exposure and toxicosis in four species of birds of prey in Massachusetts, USA, 2012-2016, in relation to use of rodenticides by pest management professionals.

511 Ecotoxicology 26: 1041-1050. Learning, Pacific Grove.

515

Millot F, Decors A, Mastain O, Quintaine T, Berny P, Vey D, Lasseur R, Bro E 2017. Field evidence of bird poisonings by imidacloprid-treated seeds: a review of incidents reported by the French SAGIR network from 1995 to 2014. Environmental and Pollution Research 24: 5469-5485.

Miljøministeriet 2015. Spredning af antikoagulante rodenticider med mus og eksponeringsrisiko for rovdyr.

521 Bekæmpelsesmiddelforskning nr. 159. (In Danish with English summary)

Montaz J, Jacquot M, Coeurdassier M 2014. Scavenging of rodent carcasses following simulated mortality due

526 Naim M, Hafidzi MN, Azhar K, Jalila A 2010. Growth performance of nestling barn owls, Tyto Alba javanica,

527 in rat baiting area inMalaysia. ARPN Journal of Agricultural and Biological Science 5:1-13.

\section{8}

529 Newton, I. 1998. Population limitation in birds. Academic Press, San Diego, California. 
531 Newton I, Wyllie I, Freestone P 1990. Rodenticides in British Barn Owls. Environmental Pollution 68: 101-117.

533 Newton I, Dale L, Finnie JK, Freestone P, Wright J, Wyatt C, Wyllie I 1999a. Wildlife and Pollution: 1997/98

534 Annual Report, JNCC Report, No. 285.

535

536 Newton I, Shore RF, Wyllie I, Birks JDS, Dale L 1999b. Empirical evidence of side-effects of rodenticides on

537 some predatory birds and mammals. In: Cowan DP, Feare CJ (eds). Advances in vertebrate pest management.

538 pp. 347-67. Filander Verlag, Fürth, Germany.

539

540 O'Bryan CJ, Braczkowski AR, Beyer HL, Carter NH, Watson JEM, McDonald-Madden E 2018. The

541 contribution of predators and scavengers to human well-being. Nature Ecology \& Evolution 2: 229-236.

542

543 Pain DJ, Pienkowski MW 1997. Farming and birds in Europe. The common agricultural policy and its

544 implications for bird conservation. Academic Press, London.

545

546 R Core Team 2015. R: A language and environment for statistical computing. R Foundation for Statistical

547 Computing, Vienna, Austria. Available from http://www.R-project.org/

548

549 Riley S, Bromley C, Poppenga R 2007. Anticoagulant exposure and notoedric mange in bobcats and mountain

550 lions in urban southern California. Journal of Wildlife Management 71: 1874-1884.

551

552 Sánchez-Barbudo IS, Camarero PR, Mateo R 2012. Primary and secondary poisoning by anticoagulant

553 rodenticides of non-target animals in Spain. Science of the Total Environment 420: 280-288.

554

555 Serieys LEK, Foley J, Owens S, Woods S, Boydston EE, Lyren LM, Poppenga RH, Clifford DL, Stephenson N,

556 Rudd J, Riley SPD 2013. Serum chemistry, hematologic, and post-mortem findings in free-ranging bobcats

557 (Lynx rufus) with notoedric mange. Journal of Parasitology 99: 989- 996.

558 
559 Serieys LEK, Lea AJ, Epeldegui M, Armenta TC, Moriarty J, VandeWoude S, Carver S, Foley J, Wayne RK,

560 Riley SPD, Uittenbogaart CH 2018. Urbanization and anticoagulant poisons promote immune dysfunction in

561 bobcats. Proceedings of the Royal Society B 285: 20172533.

562

563 Singleton G 2003. Rats, Mice and People: Rodent Biology and Management. Australian Centre for International

564 Agricultural Research.

565

566 van den Brink N 2014. Risico's van anticoagulantia rodenticides voor niet-doelsoorten en predatoren. Een scan

567 van beschikbare kennis in Europa en analyses in roofvogels uit Nederland. Alterra-rapport 2589| ISSN 1566-

568 7197. (In Dutch with English summary)

569

570 Vandenbroucke V, Bousquet-Melou A, De Backer P, Croubels S 2008. Pharmacokinetics of eight anticoagulant

571 rodenticides in mice after single oral administration. Journal of Veterinary Pharmacology and Therapeutics 31:

$572 \quad 437-45$.

573

574 Zuur A, Ieno EN, Walker N, Saveliev AA, Smith GM 2009. Mixed effects models and extensions in ecology

575 with R. Springer, New York.

576

577 


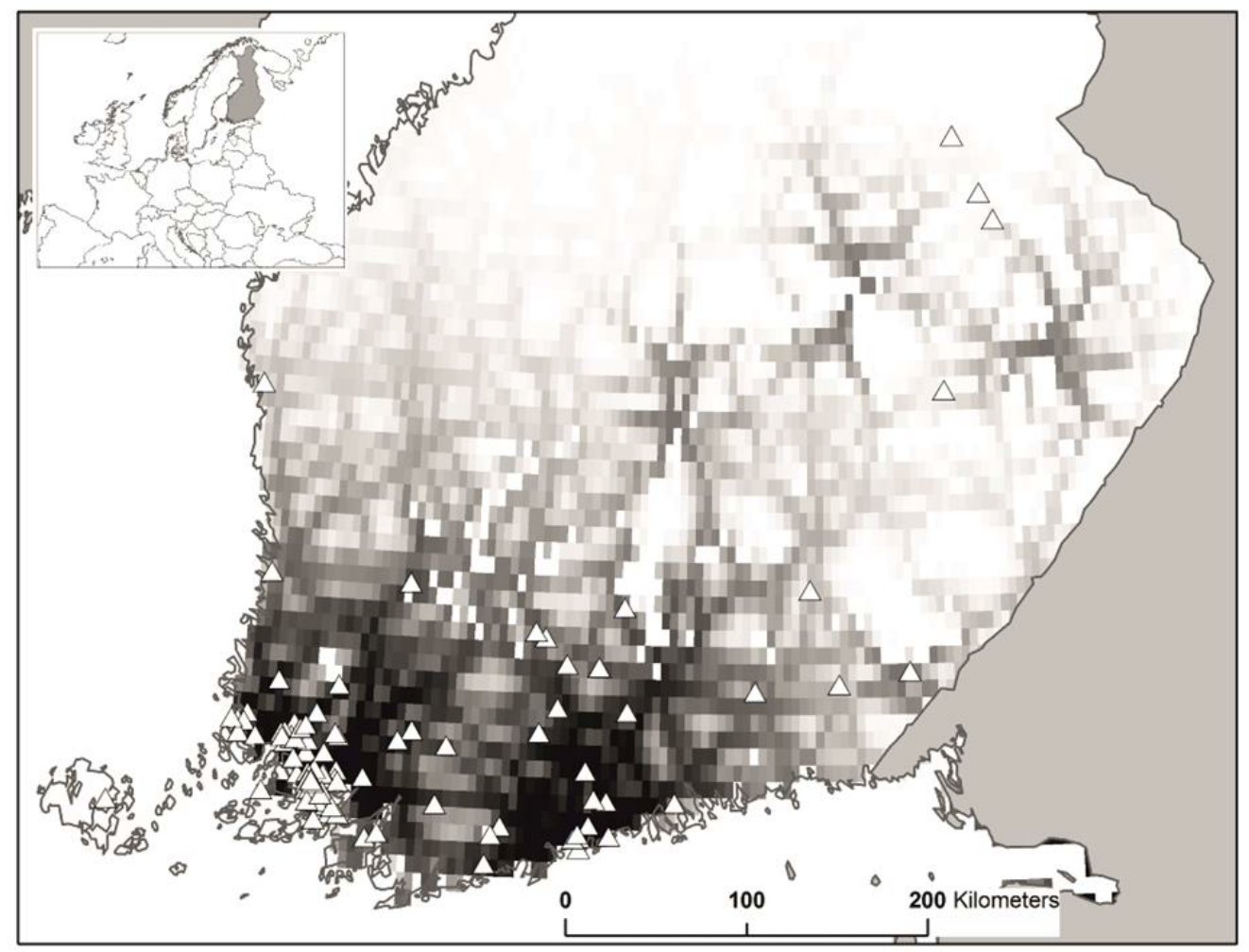

$580 \quad$ Figure 1. The location of the 131 samples (white triangles) available for this study in southern and central

581 Finland. The pixels with a black and white colour gradient depict the human accessibility of the area (data

582 retrieved from Verburg PH, Ellis EC and Letourneau A 2011. A global assessment of market accessibility and

583 market influence for global environmental change studies. Environmental Research Letters 6:034019.), from

584 highly accessible (black) to least accessible (white). The inset on the top left of the figure shows the location of

585 Finland (grey) within Europe. 
a)

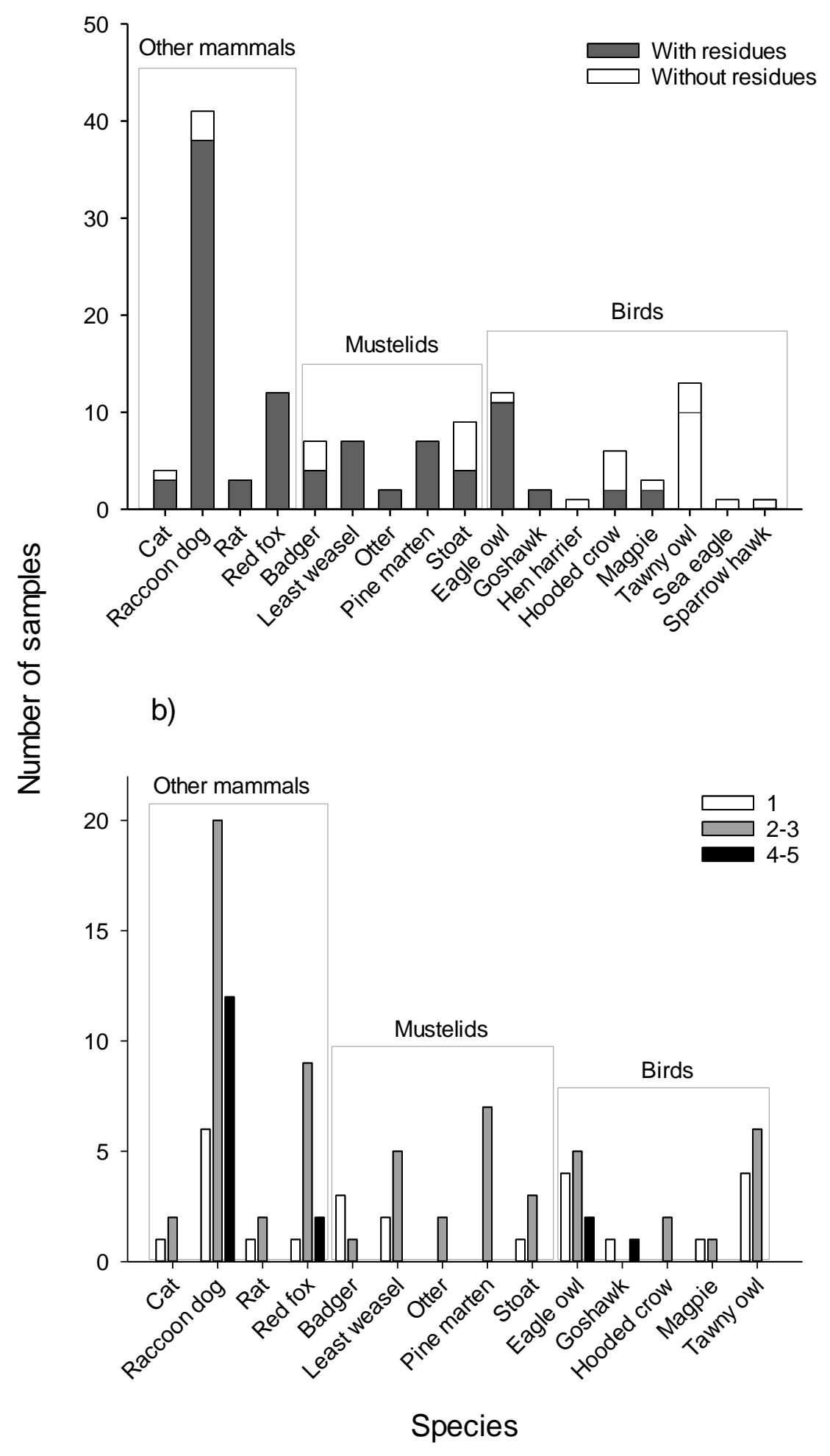

Figure 2. Number of samples $a)$ in all the analysed species with and without detected levels $(\geq 0.3 \mu \mathrm{g} / \mathrm{kg}) \mathrm{of}$ 


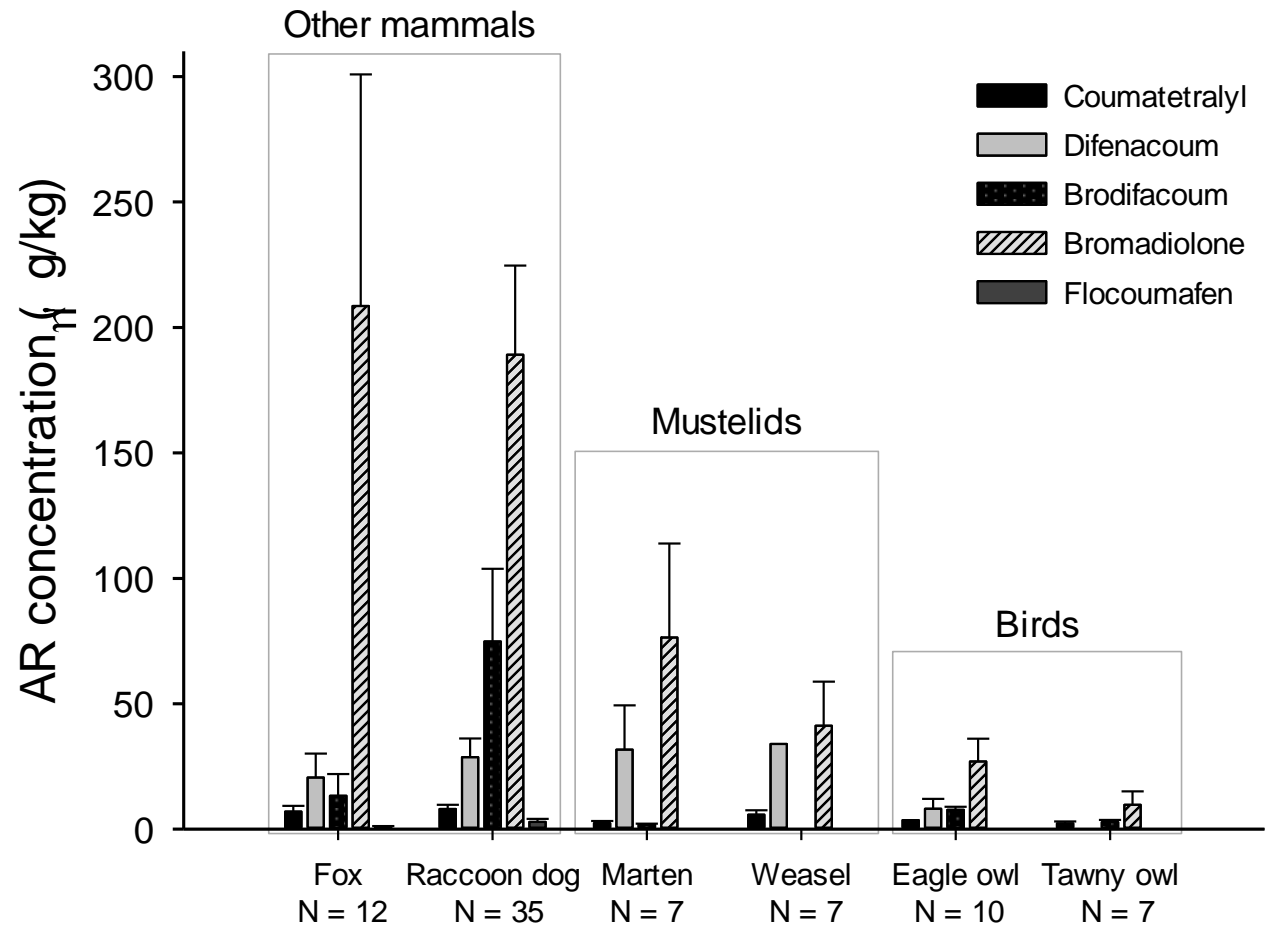

593

594 Figure 3. Concentrations (mean \pm SE) of the five detected anticoagulant rodenticides in species with highest

595 number of samples analysed. Only values $\geq 1 \mu \mathrm{g} / \mathrm{kg}$ were included (number of samples shown below). Fox $=$ red fox, marten = pine marten, weasel $=$ least weasel . 


\begin{tabular}{|c|c|c|c|c|c|c|c|c|c|c|c|c|c|c|c|c|c|c|c|c|}
\hline \multirow[b]{2}{*}{ Variables: } & \multicolumn{4}{|c|}{ AR total concentration } & \multicolumn{4}{|c|}{ AR total count } & \multicolumn{4}{|c|}{ Coumatetralyl } & \multicolumn{4}{|c|}{ Difenacoum } & \multicolumn{4}{|c|}{ Bromadiolone } \\
\hline & Coeff & SE & $\mathbf{z}$ & $p$ & Coeff & SE & $\mathbf{z}$ & $\mathbf{p}$ & Coeff & SE & $\mathbf{z}$ & p & Coeff & SE & $\mathbf{z}$ & $p$ & Coeff & SE & $\mathbf{z}$ & p \\
\hline $\begin{array}{l}\text { (Intercept) } \\
\text { Closest }\end{array}$ & 1.29 & 0.35 & 3.69 & $\varangle 0.001$ & 0.34 & 0.14 & 2.42 & 0.015 & 0.22 & 0.16 & 1.34 & 0.180 & 0.22 & 0.26 & 0.84 & 0.401 & 1.04 & 0.34 & 3.05 & 0.002 \\
\hline $\begin{array}{l}\text { industrial } \\
\text { Farms with }\end{array}$ & -0.14 & 0.17 & 0.81 & 0.416 & -0.08 & 0.07 & 1.08 & 0.282 & 0.04 & 0.07 & 0.51 & 0.609 & -0.14 & 0.12 & 1.17 & 0.241 & -0.04 & 0.18 & 0.23 & 0.816 \\
\hline $\begin{array}{l}\text { no livestock } \\
\text { Farms with }\end{array}$ & 0.13 & 0.20 & 0.66 & 0.512 & 0.09 & 0.08 & 1.00 & 0.317 & 0.12 & 0.12 & 0.99 & 0.321 & 0.15 & 0.21 & 0.71 & 0.475 & 0.10 & 0.19 & 0.51 & 0.607 \\
\hline $\begin{array}{l}\text { livestock } \\
\text { How - Road- }\end{array}$ & 0.01 & 0.19 & 0.06 & 0.953 & 0.03 & 0.08 & 0.38 & 0.703 & 0.20 & 0.08 & 2.36 & 0.018 & -0.19 & 0.18 & 1.06 & 0.289 & 0.09 & 0.18 & 0.47 & 0.638 \\
\hline $\begin{array}{l}\text { kill } \\
\text { How - Shot }\end{array}$ & 0.32 & 0.53 & 0.61 & 0.542 & 0.14 & 0.22 & 0.63 & 0.532 & -0.25 & 0.23 & 1.07 & 0.287 & 0.19 & 0.40 & 0.48 & 0.628 & 0.48 & 0.58 & 0.83 & 0.409 \\
\hline $\begin{array}{l}\text { / Trap } \\
\text { Species - } \\
\text { Other }\end{array}$ & 0.83 & 0.46 & 1.78 & 0.075 & 0.01 & 0.20 & 0.07 & 0.943 & -0.40 & 0.20 & 1.97 & 0.049 & 1.01 & 0.36 & 2.74 & 0.006 & 0.47 & 0.51 & 0.91 & 0.364 \\
\hline $\begin{array}{l}\text { mammals } \\
\text { Species - }\end{array}$ & 2.13 & 0.46 & 4.60 & $\varangle .001$ & 0.56 & 0.16 & 3.47 & 0.001 & 0.76 & 0.21 & 3.63 & $\varangle .001$ & 0.66 & 0.33 & 1.98 & 0.047 & 1.84 & 0.43 & 4.26 & $\varangle .001$ \\
\hline Mustelids & 0.99 & 0.47 & 2.07 & 0.038 & 0.03 & 0.21 & 0.12 & 0.903 & 0.46 & 0.21 & 2.22 & 0.026 & 0.03 & 0.34 & 0.08 & 0.937 & 0.73 & 0.50 & 1.45 & 0.146 \\
\hline
\end{tabular}

Table 1. The results of the effects of environmental variables (distance to the closest industrial settlement, density of farms with or without livestock), species group (birds, mustelids, other mammals) and how the sample was found (shot or trapped, road-kill, other or unknown) on the total concentration of AR, total count of ARs and on the concentration of coumatetralyl, difenacoum and bromadiolone. The reference category for species was set to be "birds", and for "How" it was set to be "other or unknown". Significant p-values (<0.05) are marked with italics. 